\title{
Manifest Anxiety and Perception of Micromomentary Expression
}

\author{
By Robert Garwood, Alexander Z. Guiora and Neil Kalter
}

$I^{N}$ A SERIES OF STUDIES Guiora ${ }^{4,5,7}$ developed the concept that empathy can be conceptualized as a comprehending modality alongside inference and intuition, and offered the following definition:

\begin{abstract}
"Empathy is a process of comprehending in which a temporary fusion of selfobject boundaries, as in the earliest pattern of object relations, permits an immediate emotional apprehension of the affective experience of another, this sensing being used by the cognitive functions to gain understanding of the other." 5
\end{abstract}

In subsequent publications $s^{6-8}$ it was suggested that empirical verification of the empathy hypothesis could best proceed by employing a research strategy that we termed transpositional.

Briefly, this research strategy requires that the process to be studied be operationalized outside the psychotherapeutic realm. The hypothesis generated in the clinical circumstance has to be "lifted out" and transposed to a behavioral realm where more rigorous, reproducible, reliable and valid experimentation is feasible. We posited that once a hypothesis generated in the clinical (naturalistic) setting could be tested out in the laboratory (the operationalized behavior), we could then hope to reapply our laboratory findings to the original circumstances.

The behavioral realm chosen was that of language behavior. Language is the most expressive, most highly developed communication modality and the most essential instrument in the clinical realm. Futhermore, language behavior provides us with a vehicle for reproducible experimentation.

The second half of our research strategy formula requires that identical processes be noted in the original and the transposed realms of behavior.

Language behavior is a unique and complex attribute of man, not only in the evolutionary sense, but in the developmental psychological history of each individual. Language behavior arises and evolves within the context of a more general psychological growth. It is reasonable to speculate that even certain structural aspects of language are in part shaped by and express the broader personality context from which they have emerged. ${ }^{\text {a }}$

Focusing on second language acquisition, and more particularly on the

From the Deartments of Psychiatry and Psychology, Neuropsychiatric Institute, and Center for Research on Language and Language Behavior, The University of Michigan, Ann Arbor, Mich.

Robert Garwoon, B.A.: Research Assistant, Department of Psychology, The University of Michigan, Ann Arbor, Mich. Alexander Z. Guiora, Ph.D.: Professor of Psychology, Departments of Psychiatry and Psychology; Chief Psychologist, Neuropsychiatric Institute; Research Associate, Center for Research on Language and Language Behavior, The University of Michigan, Ann Arbor, Mich. NeIL Kalter, A.B.: Research Assistant, Department of Psychology, The University of Michigan, Ann Arbor, Mich. 
ability to assimilate native-like authenticity of pronunciation in a foreign language, we have suggested ${ }^{6}$ that empathy may play a significant role in a learner's relative ability to acquire authenticity of pronunciation in a second language.

Thus, we have here a theory of empathy generated in the clinical circumstance, based on clinical observations and a realm of behavior outside the psychotherapeutic, namely language behavior, where the presence of the same empathic process can be postulated.

In this context Taylor et al. ${ }^{11}$ investigated the interrelationship between several variables hypothesized to be associated with empathic capacity. One measure was an empathy score derived from stories told to the TAT cards. Four advanced graduate students in clinical psychology rated the subject's (Ss) TAT stories for empathy according to Dymond's technique. ${ }^{3}$

A second technique used by Taylor et al. ${ }^{11}$ employed the use of the micromomentary expression(MME) procedure. ${ }^{6,9}$ The Ss were shown a film of a woman in a psychiatric interview, and were asked to press a button each time they observed a change of expression on the woman's face. This procedure yielded two measures: the total number of responses by each $\mathrm{S}$ (i.e. the number of times a change in expression was noted) and the number of these responses which were accurate. Accuracy was determined by having four advanced graduate students sort the 728 print-out frames of the film segment, on the basis of paired comparisons into stacks, beginning a new stack each time a change in expression occurred.

A fourth variable was the degree to which the Ss could speak an acquired language authentically. All $\mathrm{Ss}$ in the study by Taylor et al. ${ }^{11}$ were enrolled in brief foreign language courses. At the end of the course, native speaker teachers of the language studied rated five specific sentences spoken by the Ss for authenticity of pronunciation.

Taylor et al. ${ }^{11}$ reported an intercorrelation matrix of all the relevant variables. In addition they computed a multiple regression equation using authenticity of pronunciation as the criterion variable, and MME total responses, MME accuracy score, SAT verbal score and the empathy measure derived from the rating of the four TAT cards as predictor variables. This multiple regression coefficient was 0.72 . The MME accuracy score and the TAT measure each correlated with the criterion variable (authenticity of pronunciation) positively, but neither was as high as the correlation between MME total responses and authenticity of pronunciation, and this latter correlation was negative $(r=-0.60)$.

In order to account for the high negative relationship between MME total and authenticity of pronunciation, Taylor et al. ${ }^{11}$ postulated anxiety as a negative component to empathy. They reasoned that many responses to the MME task could be an indication of anxiety aroused by observing the emotional responses of the woman in the film. While the study by Taylor et al. calls for complete replication, this paper will confine itself to the investigation of this hypothesis put forth by Taylor et al. to explain the high negative correlation between MME total and authenticity of pronunciation; namely, is the MME total score an indication of anxiety? 


\section{METHODS}

Thirty Ss, 15 males and 15 females, were drawn from the unpaid subject pool at The University of Michigan. All Ss, as part of a requirement in the Introductory Psychology course, must participate as subjects in 3 hours of research. They were initially told that the experiment was to study perception and some of the processes which influence perception.

The MME task was administered first. The stimulus was the same as that used in the study by Taylor et al,, consisting of a close-up motion picture of a woman in a psychiatric interview. Only the woman's face and shoulders were visible. Three, 30 -second sequences of film had been chosen. Each film sequence was shown to the Ss four times at four different speeds, without any sound. The first two sequences were shown at speeds of 24 frames/second, $16 \mathrm{f}$./sec., $12 \mathrm{f}$./sec., and $4 \mathrm{f}$./sec. (in that order) using a Photo-optical Data Analyzer. These two trials constituted the practice runs. The third film sequence was shown at $24 \mathrm{frames} / \mathrm{second}$, again at $24 \mathrm{f}$./sec. (to provide test-retest reliability), $12 \mathrm{f} . /$ sec. and $4 \mathrm{f} . / \mathrm{sec}$. The last sequence provided the data to be analyzed with respect to the measures of anxiety.

The Ss were seated at four rows of tables placed from 10 to 30 feet in front of a projection screen. In front of each subject was a push button. The buttons were connected to an Angus-Esterline chronograph. Twenty channels were available for use; one provided a timing pulse of 1 second intervals and another channel was available to the experimentor to provide an indication of the beginning and end of each film segment.

After the subjects were seated and before the first segment began, they were read the following instructions by the experimenter.

"You are going to see a short segment of film of a woman in an interview. The same segment will be repeated three times at progressively slower speeds. I want you to note each change in facial expression you see by pushing the button on the table before you. Focus on the whole face using the mouth as little as is necessary to avoid changes due only to speaking (There will be no sound.). Note the changes in facial expression. Any questions? This first film segment is a trial rum."

The first film segment was then shown at 24 frames/second, stopped, and changed to a lower speed (16 f./sec.). This process was continued for $12 \mathrm{f}$. $/ \mathrm{sec}$. and $4 \mathrm{f}$. $/ \mathrm{sec}$. When this was finished and before the start of the second film segment, the following instructions were provided. "You will now see a second film segment at varying speeds."

"Note each change in facial expression by pushing the button." This film sequence was shown at the same four speeds as above. Before, the last segment, the subjects were told: "This is the last film segment. Press the button for each change in facial expression you see."

This final film sequence was shown at speeds of $24 \mathrm{f}$ /sec., $24 \mathrm{f}$./sec., $12 \mathrm{f}$./sec., and $4 \mathrm{f}$./ sec. The two MME measures (total responses and accurate responses) were obtained from the chronograph records.

First the Taylor Manifest Anxiety Scale (MAS) and then the Mandler-Sarason Test Anxiety Questionnaire (TAQ) were administered at the end of the session. The instructions for these tests were as follows:

"I now have several questionnaires that I would like you to fill out. The answers that you give are confidential. When you finish filling out the first questionnaire, bring it to me and I will give you the second. At the top of each please use the following code:

(1) first letter of your mother's first name

(2) first letter of your father's first name

(3) day of birth 
(4) $\mathrm{M}$ for male or $\mathrm{F}$ for female

At the top of the first questionnaire record the number of the box at which you are sitting. Any questions?"

\section{Results}

Pearson correlations were computed between MME total obtained at each of the four presentations of the final sequence of the film and each of the two anxiety scales, and between MME accuracy scores also at each of these four film presentations and the anxiety scales. These correlations were uniformly low, ranging between -0.19 (MME total at $24 \mathrm{f}$./sec. with the MAS and MME accurate at $12 \mathrm{f} . / \mathrm{sec}$. with the MAS) and 0.00 (MME total, second presentation at $24 \mathrm{f}$./ $\mathrm{sec}$. with the TAQ). None of the correlations approached significance at the 0.05 level.

Because the distributions of MME scores evidenced a high degree of positive skew, it was felt that the obtained correlations could be artifactual. ${ }^{10}$ As such a square root transformation (to reduce the skew) was carried out. Correlations between the MME measures and the anxiety tests were recalculated. However, these correlations were basically the same, varying only by \pm 0.02 . The degree of skew was not great enough and/or the number of Ss was not large enough, to render the correlations based on the untransformed distributions artifactual.

\section{Discussion}

The uniformly low, noasignificant correlations between MME total scores, obtained at varying film speeds and the MAS and TAQ do not corroborate the hypothesis by Taylor et al. ${ }^{11}$ that many MME responses may be taken as an indication of anxiety. Anxiety as measured by these two paper and pencil tests bear no relationship to MME total score. Furthermore, MME accuracy scores which, if the Taylor et al. hypothesis were correct, should also be negatively correlated with the anxiety tests, bore no relationship to these tests.

While MME total may have been related to authenticity of foreign language pronunciation in our sample, as they were in the Taylor et al. ${ }^{11}$ study (a portion of their study not replicated here), the fact would still remain that the MME total scores (at all speeds of the film) were not related to the MAS or the TAQ. One must assume that either (1) the initial finding by Taylor et al. of a high negative correlation between MME total and authenticity of pronunciation was due to chance. (2) MME total score is not an indicator of anxiety, at least as measured by the MAS and TAQ, or, (3) a negative relationship between MME total and authenticity of pronunciation, if it "really exists" (i.e. is replicable), is due to some factor other than anxiety.

The latter two points require further discussion. Assuming the initial findings by Taylor et al. ${ }^{11}$ can be replicated, it is possible that anxiety can still be used to explain them. But it would be an ephemeral anxiety aroused by the film which would decay too rapidly to be measured by paper and pencil tests of anxiety administered several minutes later. Before the Taylor et al. hypothesis of anxiety as a negative component to empathy can be laid to rest, a further study perhaps using GSR responses, while the Ss are viewing the film, could 
be carried out. GSR responses, as a measure of anxiety at the time of viewing the film, could be correlated with MME total. If this correlation were nonsignificant, the Taylor et al. anxiety hypothesis could be abandoned with confidence.

An interesting piece of datum came to light by talking informally to the Ss after the experimental procedures were completed. They reported feeling bored and angry while in the experimental condition. It is possible to argue that these subjective experiences may be derivatives of defenses against anxiety stirred up by viewing the emotional reaction of the woman in the film. However, it may be that Ss do become quite bored and annoyed while sitting through several repetitions of the same film. Some Ss may simply "turn off" on the experimental procedure and just repetitively push the button without attending to the film. If this is the case, finding by Taylor et al. ${ }^{11}$ of a negative correlation between MME total and authenticity of pronunciation may reflect a persistence factor: Ss who are highly motivated to do well or to achieve learn authentic pronunciation of a second language well, and remain involved (persist) in the experimental task. ${ }^{2}$ despite feeling bored or annoyed by the task.

\section{REFERENCES}

1. Bell Telephone Laboratory: Action pictures of sound: a portrayal of dynamic spectra. Pattern display by cathode ray sound spectroscope. Film produced by the Transmission Department of Bell Telephone Laboratory, 1947.

2. Birch, D.: Shift in activity and the concept of persisting tendency. In Spence, K. W., and Spence, J. (Eds.): The psychology of learning and motivation. New York, Academic Press, 1968.

3. Dymond, R. A.: A scale for the measurement of empathic ability. J. Consult. Psychol. 13:127-133, 1949.

4. Guiora, A. Z., Bolin, R., Dutton, C., and Meer, R.: Intuition, a preliminary statement. Psychiat. Quart. [Suppl.] 39:110-122, 1965.

5. - : On clinical diagnosis and prediction. Psychol. Rep. 17:779-784, 1965.

6. -, Lane, H. L., and Bosworth, L. A.: An exploration of some personality variables in authentic pronunciation of a second language. In Lane, H. L., and Zale, E. M. (Eds.): Studies in Language and Language Behavior. Progress Report IV. Ann Arbor, Mich. Center for Research on Language and Language Behavior, 1967.

7. - : Toward a systematic study of empathy. Compr. Psychiat. 8:375-385, 1968.

7a. -, Taylor, L. L., and Brandwin, M. A.: A contribution to the psychology of second language behavior. Proceedings of the Sixteenth International Congress of Applied Psychology, Amsterdam, Swets and Zeitlinger, 585-588, 1969.

8. -: Transpositional research in the clinical process. Compr. Psychiat. 11:531, 1970.

9. Haggard, L. A., and Isaacs, R. S.: Micromomentary facial expressions as indicators of ego mechanisms in psychotherapy. In Gottschalk, L. A., and Auerbach, A. H. (Eds.): Methods of Research in Psychotherapy. New York, AppletonCentury Crofts, 1966.

10. Mueller, C. G.: Numerical transformation in the analysis of experimental data. Psychol. Bulletin. 46:198-223, 1949.

11. Taylor, L. L., Guiora, A. Z., Catford, J. C., and Lane, H. L.: The role of personality variables in second language behavior. Compr. Psychiat. 10:463-474, 1969. 